\title{
La tuberculosis: un viejo problema aún sin resolver... ¿para cuándo una nueva vacuna?
}

La tuberculosis humana es una de las enfermedades más antiguas que se conocen. Las primeras lesiones tuberculosas datan de restos procedentes del Neolítico, se trata de varias vértebras dorsales pertenecientes a un adulto joven que vivió hacia el año 5.000 a.C. A lo largo de la historia, esta enfermedad ha acompañado al hombre cobrándose gran cantidad de vidas humanas, en el siglo XVII en Europa se hablaba de la epidemia de tuberculosis como la gran Plaga Blanca, y era posiblemente la primera causa de muerte de la población. Hubo que esperar hasta el siglo XIX para conocer cuál era la causa de esta enfermedad, el 24 de marzo de 1882 el microbiólogo alemán Robert Koch dio a conocer sus descubrimientos sobre el bacilo causante de la tuberculosis en material infectado. Unos años más tarde, en 1921, Albert Calmette y Camille Guérin lograron la atenuación del bacilo tuberculoso vivo, el BCG, que dio nombre a la vacuna, la cual se empezó a utilizar masivamente después de la Segunda Guerra Mundial, debido al importante aumento de las muertes por tuberculosis ${ }^{1}$.

La BCG, única vacuna antituberculosa disponible, ha sido la vacuna más utilizada a nivel mundial (actualmente se administra a unos 100 millones de niños cada año). Pero, a pesar de su amplia utilización y de los importantes avances que se han producido en los últimos años en el conocimiento de esta enfermedad, y que han supuesto la reducción de la mortalidad global de tuberculosis (TB) en más del 40\% desde 1990, así como la disminución de su incidencia, la carga mundial de TB sigue siendo muy alta. Según datos de la Organización Mundial de la Salud (OMS), en 2011 hubo 8,7 millones de casos nuevos de TB y 1,4 millones de personas murieron por esta causa. En niños, las cifras son igualmente preocupantes, se produjeron medio millón de casos y 64.000 muertes en el mismo periodo. A nivel mundial, la TB sigue siendo una enfermedad vinculada con la pobreza, más del $95 \%$ de las muertes ocurrieron en países con ingresos bajos y medianos ${ }^{2}$.

Hoy en día, los principales problemas a los que se enfrenta la lucha contra esta enfermedad son los siguientes:

- La BCG es una vacuna controvertida, ya que hay datos contradictorios en cuanto a su eficacia protectora. Está documentado su efecto protector en niños contra la meningitis tuberculosa y la tuberculosis diseminada, sin embargo no evita la infección primaria y tampoco impide la reactivación de la infección pulmonar latente, que es la principal fuente de propagación del bacilo tuberculoso ${ }^{3}$.

- Los progresos en la lucha contra la TB multi y ultrarresistente (TB-MR y TB-XR) siguen siendo lentos. Según cálculos de la OMS, el 3,7\% de los nuevos casos de TB a nivel mundial y el $20 \%$ de los tratados anteriormente tienen TB-MR ${ }^{4}$. Casi el $60 \%$ de los casos notificados de TB-MR en 2011 corresponden a la India, China y la Federación de Rusia. Se cree que aproximadamente el 9\% de los casos de TB-MR presentan TB-XR.
- La coinfección por el bacilo tuberculoso y el VIH constituye un grave problema para el control de la TB en las zonas donde la infección por VIH es frecuente. La TB es la causa más importante de mortalidad entre las personas que viven con el VIH/SIDA, además las personas doblemente infectadas tienen entre 21 y 34 veces más probabilidades de padecer TB activa que las personas no infectadas con el VIH. Según datos de la OMS, en 2011 unas 430.000 personas en todo el mundo murieron como consecuencia de TB asociada a la infección por VIH. En el mismo período habría aproximadamente 1,1 millones de casos nuevos de esta coinfección, siendo el África subsahariana la región más afectada .

Para conseguir el control de esta enfermedad y poder alcanzar las metas propuestas por la Alianza «Alto a la tuberculosis» (reducir la prevalencia y la mortalidad por TB en un $50 \%$ respecto a 1990 para 2015 y eliminar la TB como un problema de salud pública para 2050, 1 caso por millón de habitantes), es necesario, entre otras medidas, promover el desarrollo de nuevos métodos diagnósticos, medicamentos y vacunas ${ }^{6}$.

En cuanto al desarrollo de vacunas, existe una necesidad urgente de una nueva vacuna segura y eficaz para todas las formas de TB, incluidas las resistentes a fármacos y las vacunas terapéuticas, que puedan disminuir la duración del tratamiento tuberculoso o reducir las recaídas tras el mismo. En el desarrollo de las vacunas preventivas hay dos líneas de investigación: la primera busca mejorar mediante revacunación la protección conferida por la BCG, y la segunda se centra en el desarrollo de nuevas vacunas capaces de sustituir a la actual BCG. En la actualidad hay 12 ensayos clínicos en marcha, dos de ellos, en los que se busca mejorar la inmunidad conferida por la BCG se encuentran en fases más avanzadas (fase IIb): la vacuna MVA85A (constituida por un virus Vaccinia Ankara modificado para expresar el antígeno 85A) y vacuna AERAS-402 (basada en un adenovirus serotipo 35 expresando varios antígenos del bacilo de la tuberculosis $)^{7,8}$.

Recientemente se han publicado los datos del ensayo clínico llevado a cabo en Ciudad del Cabo con la vacuna MVA85A, desarrollada por investigadores de la Universidad de Oxford (Reino Unido) en el que se estudia la seguridad y la eficacia de esta vacuna frente a la enfermedad y la infección tuberculosa en niños de 4 a 6 meses que previamente habían sido vacunados con BCG. Los resultados confirman que es una vacuna bien tolerada, pero induce una modesta respuesta inmune en los niños vacunados (la eficacia frente a la enfermedad es del 17.3\% (IC 95\%: -31.9 a 48.2) y frente a la infección del -3,8\% (IC 95\%: -28.1 a 15.9$)^{9}$.

En el camino hacia el desarrollo de una nueva vacuna frente a la TB, destacan los trabajos que están realizando un grupo de investigadores españoles liderados por Carlos Martín Montañés, Catedrático de Microbiología de la Universidad de Zara- 


\section{Editorial}

goza, en colaboración con el Instituto Pasteur. La vacuna que desarrolla este grupo de españoles, MTBVAC, que se encuentra en fase I, está basada en la atenuación genética del Micobacterium tuberculosis por la eliminación de dos genes de virulencia independientes fadD26 y phoP. Esta vacuna, que busca reemplazar a la BCG, es un firme candidato para convertirse en una alternativa eficaz frente a la única vacuna antituberculosa disponible en la actualidad.

Después de 100 años del descubrimiento de la BCG, las nuevas investigaciones en curso abren una puerta a la esperanza para el desarrollo de una nueva vacuna frente a la TB. Según la OMS, asumiendo que uno de los candidatos más avanzados tuviera una eficacia suficiente, la nueva vacuna frente a esta enfermedad podría estar disponible en $2018^{7}$.

\section{G. Gema Cáceres Bermejo \\ Comandante Médico}

Instituto de Medicina Preventiva de la Defensa

\section{BIBLIOGRAFÍA}

1. Báguena MJ. La tuberculosis en la historia. An. R. Acad. Med. Comunitat Valenciana, 2011. Disponible en http://www.ramcv.com/50-anales2011.html

2. OMS.Campañas mundiales de salud pública de la OMS. Día Mundial de la Tuberculosis 24 de marzo de 2013. Disponible en http://www.who.int/campaigns/tb-day/2013/event/es/index.html

3. La vacuna antituberculosa. Documento de posición de la OMS. Disponible en http://www.who.int/immunization/wer7904BCG_Jan04_position_paper_SP.pdf

4. OMS. Informe mundial sobre la tuberculosis 2012. Disponible en http://www. who.int/tb/publications/global_report/gtbr12_executivesummary_es..pdf

5. OMS. Tuberculosis. Nota descriptiva $N^{\circ} 104$. Octubre de 2012. Disponible en http://www.who.int/mediacentre/factsheets/fs104/es/index.html

6. OMS. Estrategia Alto a la tuberculosis. Disponible en http://www.who.int/tb/ strategy/stop_tb_strategy/es/index.html

7. OMS. Tuberculosis vaccines. Disponible en http://www.who.int/vaccine_research/development/tuberculosis/en/index.html

8. Martín C, Gicquel B. New tuberculosis vaccines. Enferm Infecc Microbiol Clin 2011;29(Supl 1):57-62.

9. Tameris M, Hatherill M, Landry B, Scriba T, Snowden M, Lockhart S et al. The Lancet published on line February 4, 2013. Disponible en http://dx.doi. org/10.1016/S0140-6736(13)60177-4 